\title{
Inhibition of farnesyl pyrophosphate synthase attenuates high glucose-induced vascular smooth muscle cells proliferation
}

\author{
GUO-PING CHEN ${ }^{1}$, XIAO-QIN ZHANG ${ }^{2}$, TAO WU $^{3}$, JIE HAN $^{3}$ and DAN YE ${ }^{1}$ \\ ${ }^{1}$ Department of Endocrinology, The First Affiliated Hospital, \\ College of Medicine, Zhejiang University, Hangzhou, Zhejiang 310003 ; ${ }^{2}$ Department of \\ Respirology, Zhejiang Provincial People's Hospital, Hangzhou, Zhejiang 310014; ${ }^{3}$ Institute of Cardiology, \\ The First Affiliated Hospital, College of Medicine, Zhejiang University, Hangzhou, Zhejiang 310003, P.R. China
}

Received August 1, 2016; Accepted March 13, 2017

DOI: $10.3892 / \mathrm{mmr} .2017 .6360$

\begin{abstract}
The proliferation of vascular smooth muscle cells (VSMCs) is one of the main features of atherosclerosis accelerated by hyperglycemia. Our previous studies found that farnesyl pyrophosphate synthase (FPPS, EC 2.5.1.10), an essential enzyme in the mevalonate pathway, was upregulated in aorta media from diabetic mice along with the process of atherosclerosis. However, the exact role of FPPS in high glucose-induced proliferation of VSMCs is largely unclear. In our study, we found that alendronate (an FPPS inhibitor) attenuated diabetic accelerated atherosclerosis in vivo and suppressed high glucose-induced VSMCs proliferation in vitro. Moreover, in aorta from streptozotocin (STZ)-induced diabetic mice, 16-week treatment of alendronate decreased the activation of small GTPase (Ras, RhoA, and Rac1), but had no effect on the expression of cystathionine $\gamma$-lyase (CSE), the pivotal $\mathrm{H}_{2} \mathrm{~S}$-producing enzyme. Meanwhile, in VSMCs cultured in high glucose-containing media, alendronate remarkably decreased total CoQ content, increased the $\mathrm{H}_{2} \mathrm{~S}$ level, depressed small GTPases (Ras, RhoA, and Rac1) activation, but yet had no effect on expression of CSE. In conclusion, FPPS inhibition by alendronate attenuated the high glucose-induced proliferation of VSMCs both in vivo and in vitro, probably though depressing $\mathrm{H}_{2} \mathrm{~S}$ metabolism and suppressing small GTPases (Ras, RhoA, and Rac1) activation.
\end{abstract}

\section{Introduction}

Patients with diabetes exhibit an increased susceptibility to develop a wide range of macro-vascular complications, including atherosclerotic cardiovascular and cerebrovascular

Correspondence to: Ms. Dan Ye, Department of Endocrinology, The First Affiliated Hospital, College of Medicine, Zhejiang University, 79 Qinchun Road, Hangzhou, Zhejiang 310003, P.R. China

E-mail: appleanne@zju.edu.cn

Key words: farnesyl pyrophosphate synthase, vascular smooth muscle cells, proliferation, high glucose, $\mathrm{H}_{2} \mathrm{~S}$, small GTPase disease, which account for the majority of deaths and disability in diabetes patients $(1,2)$. Improving macro-vascular outcomes through glucose-lowering interventions have remained a difficult, complicated, and to date, largely unsuccessful enterprise. There is an ongoing need for new therapeutic targets which would slow the accelerated progression of diabetic atherosclerosis (3).

The elevated blood glucose level (hyperglycemia) is considered one of the major causes of accelerated atherosclerosis in diabetes $(4,5)$. Together with endothelial dysfunction, the proliferation of vascular smooth muscle cells (VSMCs) is one of the characteristic features of atherosclerosis (6). Under high glucose conditions, human, porcine and rodent VSMCs proliferate and migrate from the media to the subendothelial space of the vessel wall where early atherosclerotic lesions are localized $(5,6)$. However, the mechanisms underlying VSMCs proliferation are very complicated and have not yet been completely elucidated.

Farnesyl pyrophosphate synthase (FPPS, EC 2.5.1.10), an essential enzyme in the mevalonate pathway, catalyzes the synthesis of FPP (7). As seen in Fig. 1, FPP is a crucial branching point precursor in the synthesis of several classes of essential metabolites, including sterols (such as cholesterol), ubiquinones (also known as coenzyme Q, CoQ) and non-sterols substrates for prenylation of proteins (especially the small GTPases) (7-9). These metabolites serve as the basis for the biosynthesis of molecules used in processes as diverse as terpenoid synthesis, protein prenylation, cell membrane maintenance, hormones, protein anchoring, N-glycosylation, and steroid biosynthesis (10). In our previous studies, we found that the FPPS expression in aorta from streptozotocin (STZ)-induced diabetic mice was remarkably upregulated along with the accelerated process of atherosclerosis (11). Meanwhile, we also observed that high glucose $(22.2 \mathrm{mM})$ induced both VSMCs proliferation and FPPS upregulation in vitro (11). Thus, we assumed that increased expression of aortic FPPS may contribute to the accelerated atherogenic process in diabetic mice. However, its exact relationship and mechanisms remain to be explored.

Therefore, the present study was designed to determine whether the inhibition of FPPS attenuated high glucose-induced VSMCs proliferation in vivo or in vitro, and if present, to investigate the underlying mechanisms. For this purpose, alendronate, an inhibitor of FPPS in mevalonate 
pathway $(12,13)$, was used to examine the potentially critical roles of FPPS in VSMCs proliferation during the accelerated atherogenic process in diabetes mellitus.

\section{Materials and methods}

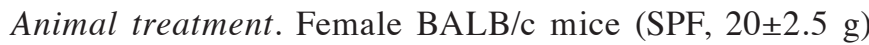
were purchased from the Shanghai Laboratory Animal Center (Chinese Academy of Sciences), and housed in a pathogenfree laboratory at the First Affiliated Hospital of Zhejiang University. The procedures and protocols of the study conformed to the Guide for the Care and Use of Laboratory Animal published by the US National Institutes of Health (NIH Publication no. 85-23, revised 1996) and the guidelines of the Animal Care and Use Committee of Zhejiang University. All chemicals and reagents were purchased from Sigma (S. Louis, MO, USA), unless otherwise stated. As described in our previous report (11), diabetic mice were induced by daily injection of STZ at a dose of $50 \mathrm{mg} / \mathrm{kg}$ for 5 days after a $4 \mathrm{~h}$ fast. Non-diabetic mice received the vehicle (citrate buffer; 0.05 M, pH 4.5). Twelve diabetic mice were randomly divided into two groups as follows: i) Diabetic mice treated with distilled water (control) group $(D+C, n=6)$; ii) diabetic mice treated with alendronate $(15 \mathrm{mg} / \mathrm{kg} /$ day $)$ group $(\mathrm{D}+\mathrm{A}, \mathrm{n}=6)$. Twelve age and weight matched non-diabetes mice were also divided to control and alendronate group (ND+C and $\mathrm{ND}+\mathrm{A}, \mathrm{n}=6$ ). Alendronate was administrated every day for 16 weeks by the intragastric route.

Glucose and lipid analysis. Fasting blood glucose (FBG) levels were evaluated in venous blood drawn from the tail by using a CONTOUR glucose meter (Bayer, Mishawaka, IN, USA). Serum total cholesterol (TC), high-density lipoprotein cholesterol (HDL-C), low-density lipoprotein cholesterol (LDL-C), and triglyceride (TG) concentrations were determined by commercial enzymatic methods (test kits from Shanghai Rongsheng Biotech, Inc., Shanghai, China).

Histological analysis. The aorta was dissected in situ from the ascending aorta to the iliac bifurcation, cleaned of peripheral fat under a dissecting microscope, and then fixed in 10\% neutral formalin, embedded in paraffin, and sequentially stained with hematoxylin and eosin. Lesion areas (LA) per section were counted by taking the average of 6 sections spaced $30 \mu \mathrm{m}$ apart, beginning at the base of the aortic root. Media thickness (MT) at 10 different points of the thoracic aorta was measured and calculated. Morphometric analysis above was performed with Image-Pro Plus 6.0.

Cell culture and treatments. VSMCs were isolated from thoracic aortic explants of female BALB/c mice as previously described $(11,14)$. In brief, aortic explants were cultured in Dulbecco's modified Eagle's medium (DMEM; Gibco, Grand Island, NY, USA) supplemented with $10 \%$ fetal bovine serum (FBS; Gibco) and maintained at $37^{\circ} \mathrm{C}$ in a humidified atmosphere of $5 \% \mathrm{CO}_{2}$ and $95 \%$ air. After 2 weeks, cells that had migrated onto the tissue culturedish were collected by trypsinization and subcultured successively. The identity of the VSMCs was determined by the positive immunocytochemistry reactivity to smooth muscle specific $\alpha$-actin. To ensure the consistency of results, passages 5-12 of VSMCs were used for experiment. According to our previous report (11), VSMCs proliferation was induced by culturing cells in diabetic medium containing $22.2 \mathrm{mM}$ glucose. Mannitol was used as an osmotic control. VSMCs were also cultured in the presence of various concentrations of alendronate $(0,3,10,30$ and $100 \mu \mathrm{M})$ for $72 \mathrm{~h}$.

Cell proliferation assay. After above treatments, cell proliferation was assessed by 3-[4,5-dimethylthiazol-2-yl]-2,5-diphenyltetrazolium bromide (MTT) assay as described previously (11). Cells were cultured in 96-well plates $\left(5 \times 10^{3}\right.$ cells/well). When the VSMCs reached a $60 \%$ confluent state, different treatments as stated above were given. Then the cells of 96 wells were incubated with $100 \mu \mathrm{l}$ of $0.5 \mathrm{mg} / \mathrm{ml}$ MTT at $37^{\circ} \mathrm{C}$ for $4 \mathrm{~h}$, washed with cold PBS, and lysed with $100 \mu \mathrm{l}$ of DMSO. After the insoluble crystals were completely dissolved, the optical density of each well was immediately measured at $570 \mathrm{~nm}$ using an automatic microplate reader (Molecular Devices, Sunnyvale, CA, USA).

Western blot analysis. Total proteins were isolated from the aortic media (VSMCs were the only cell type in this layer) or cultured VSMCs, and the procedure of western blot analysis was performed as described in our previous reports $(11,15)$. $10 \mu \mathrm{g}$ protein from each sample was separated on $10 \%$ sodium dodecyl sulphate-polyacrylamide gel, electrophoresed, and transferred onto nitrocellulose membranes. The membrane was blocked with Tris-buffered saline (TBS, $\mathrm{pH}$ 7.6) containing $5 \%$ skim milk and $0.05 \%$ Tween-20, and then incubated with specific antibodies for $12 \mathrm{~h}$ at $4^{\circ} \mathrm{C}$. The expressions of $\mathrm{H}_{2} \mathrm{~S}$-producing enzyme [cystathionine $\gamma$-lyase (CSE)] and total small GTPases (Ras, RhoA, and Rac1) were detected using their specific antibodies: mouse anti-CSE monoclonal antibody (1:1,000, sc-374249; Santa Cruz Biotechnology Co., Ltd., Japan), rabbit anti-Rac1 polyclonal antibody (1:1,000, sc-95; Santa Cruz Biotechnology Co., Ltd.), rabbit anti-RhoA monoclonal antibody (1:2,000, 2117; Cell Signaling Technology, Inc., Danvers, MA, USA), and rabbit anti-Ras monoclonal antibody (1:2,000, 3,339; Cell Signaling Technology, Inc.). To ensure equal protein loading, mouse monoclonal antibody to $\beta$-actin (1:5,000, ab8226; Abcam, Cambridge, UK) was used as an endogenous control. After the membrane was incubated with goat-anti-rabbit IgG conjugated to horseradish peroxidase (1:5,000 dilution; MultiSciences, Hangzhou, China) for $1 \mathrm{~h}$ at $37{ }^{\circ} \mathrm{C}$, the immune complexes were visualized by the enhanced chemiluminescence (ECL) method. Quantification of the bands was carried out using densitometric analysis software Quantity One (Bio-Rad, Berkeley, CA, USA).

Small GTPases activation assay. Small GTPase (Ras, RhoA, or Rac1) activation was determined from tissue or cell lysates using Ras, RhoA, or Rac1 activation G-LISA kit (BK131, BK124, BK128; Cytoskeleton, Denver, CO, USA) according to the manufacturer's instruction. The signal was measured at $490 \mathrm{~nm}$ with a microplate spectrophotometer. Results are expressed as fold increase in activity compared with control group.

CoQ quantification. Concentrations of total $\mathrm{CoQ}_{9}$ and $\mathrm{CoQ}_{10}$ were determined by isocratic high-performance liquid 


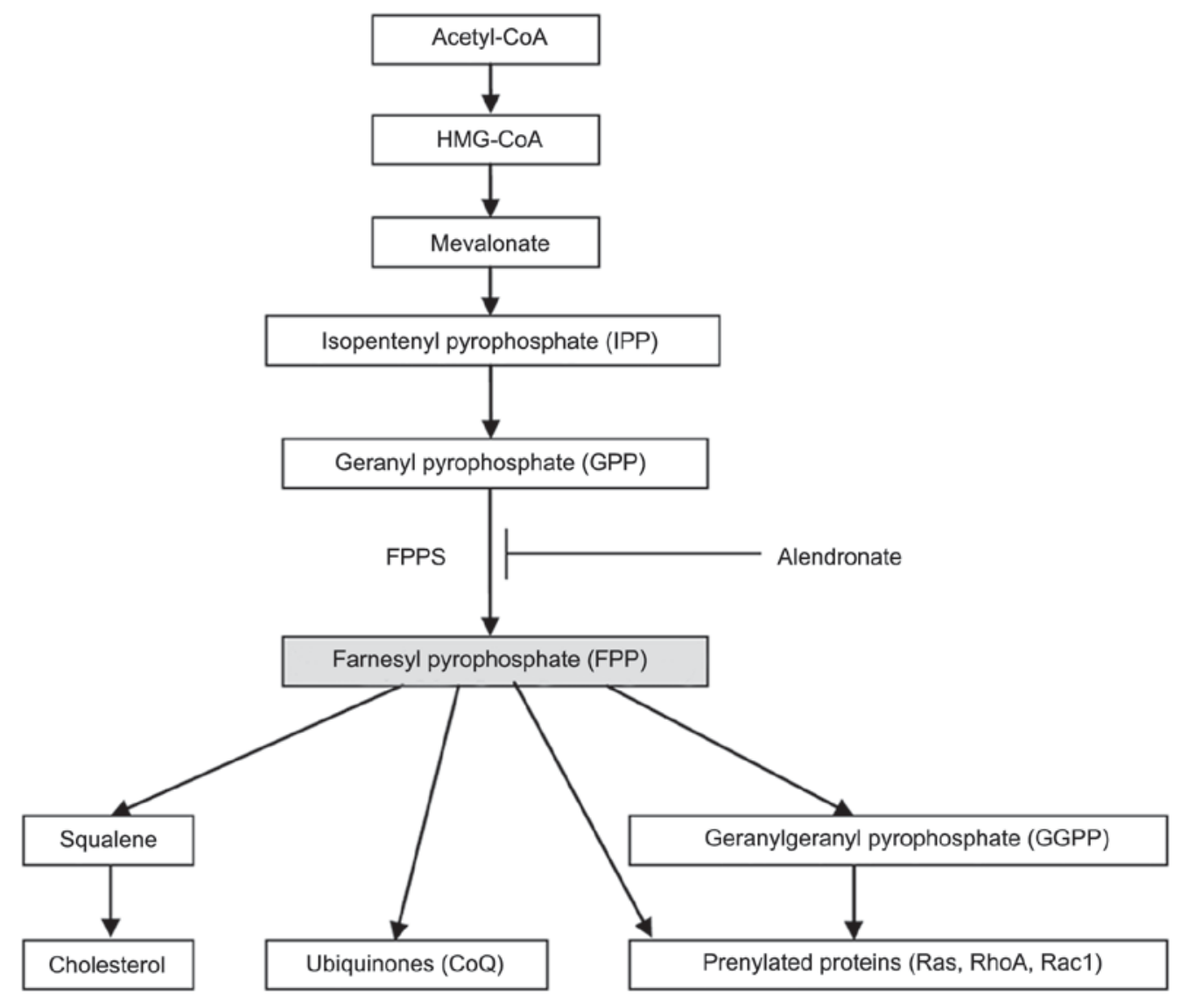

Figure 1. Schematic diagram of the mevalonate pathway.

chromatography (HPLC) according to Lang et al (16) with some modifications as follows. Cells were cultured in 12-well plates $\left(1 \times 10^{5}\right.$ cells/well). When the VSMCs reached a $60 \%$ confluent state, different treatments as stated above were given. Cells were resuspended and lysed in ultrapure water with addition of 1,4-benzoquinone ( $2 \mathrm{mg} / \mathrm{ml}$ in ethanol) to allow a complete oxidation of ubiquinol (reduced form of CoQ). The mixtures were then extracted twice by hexane/ethanol $(5 / 2, \mathrm{v} / \mathrm{v})$. Collected organic layers were evaporated under nitrogen, and the dried compounds were dissolved in ethanol and injected on the column Agilent TC-C18 (15 cmx0.46 cm, id $5 \mu \mathrm{m}$; Agilent Technologies, Inc., Palo Alto, CA, USA). All steps of sample preparation were carried out rapidly, on ice, with protection from light. The mobile phase consisted of methanol/acetonitrile/ethanol $(6 / 2 / 2, \mathrm{v} / \mathrm{v} / \mathrm{v})$, and the isocratic elution carried out at $1 \mathrm{ml} / \mathrm{min}$. The concentrations of compounds were detected spectrophotometrically at $275 \mathrm{~nm}$ using external standards $\mathrm{CoQ}_{11}$ and expressed as nmol per gram of protein (the residue mixtures were also dried under nitrogen and subjected to the protein analysis).

Measurement of Hydrogen sulfide $\left(\mathrm{H}_{2} \mathrm{~S}\right)$ concentration. $\mathrm{H}_{2} \mathrm{~S}$ concentrations were measured in cultured medium as described previously (17). Briefly, after different treatments, cultured medium was collected from VSMCs plate. $75 \mu 1$ medium was mixed with $250 \mu \mathrm{l}$ of $1 \%$ (w/v) zinc acetate and $425 \mu \mathrm{l}$ distilled water in a glass test tube. Then $20 \mathrm{mM}$ $\mathrm{N}, \mathrm{N}$-dimethyl-p-phenylenediamine sulfate in $7.2 \mathrm{mM} \mathrm{HCl}$
(133 $\mu \mathrm{l})$ and $30 \mathrm{mM} \mathrm{FeCl}_{3}$ in $1.2 \mathrm{mM} \mathrm{HCl} \mathrm{(133 \mu l)} \mathrm{were} \mathrm{also}$ added to the test tube for $10 \mathrm{~min}$ incubation at room temperature. The protein in the medium was removed by adding $250 \mu \mathrm{l}$ of $10 \%$ trichloroacetic acid to the reaction mixture and pelleted by centrifugation at $14,000 \mathrm{~g}(5 \mathrm{~min})$. The absorbance of the resulting solution at $670 \mathrm{~nm}$ was measured with a spectrophotometer (Molecular Devices) in a 96-well plate. All samples were assayed in duplicate, and concentration of $\mathrm{H}_{2} \mathrm{~S}$ in the solution was calculated against a calibration curve of NaHS (3.125-250 $\mu \mathrm{M})$.

Statistical analysis. All experiments were performed at least three times, and the results were expressed as mean \pm standard errors of mean (SEM). All analyses were performed with SPSS (version 13.0; SPSS, Inc., Chicago, IL, USA). One-way analysis of variance (ANOVA) followed by Bonferroni post hoc test was used to determine significant differences between groups. $\mathrm{P}<0.05$ was considered to indicate a statistically significant difference.

\section{Results}

Alendronate had no effect on glucose and lipid levels. As expected the STZ-induced diabetic mice had extremely higher levels of glucose than age-matched control mice. 16-week treatment with alendronate had no effect on glucose levels in neither diabetic nor non-diabetic groups (Table I). Then, in all groups, serum lipid levels (TC, LDL-C, HDL-C, and TG) were comparable (Table I). 
Table I. Effect of alendronate treatment on glucose and lipid levels.

\begin{tabular}{lccccc}
\hline Group & FBG $(\mathrm{mM})$ & TC $(\mathrm{mM})$ & HDL-C $(\mathrm{mM})$ & LDL-C $(\mathrm{mM})$ & TG $(\mathrm{mM})$ \\
\hline $\begin{array}{l}\text { Non-diabetic mice } \\
\text { Control }\end{array}$ & $7.62 \pm 0.53$ & $1.76 \pm 0.07$ & $0.87 \pm 0.07$ & $0.56 \pm 0.05$ & $1.42 \pm 0.07$ \\
$\quad$ Alendronate & $7.68 \pm 0.67$ & $1.85 \pm 0.07$ & $0.81 \pm 0.06$ & $0.54 \pm 0.06$ & $1.33 \pm 0.06$ \\
Diabetic mice & & & & \\
$\quad$ Control & $22.54 \pm 1.71^{\mathrm{a}}$ & $1.90 \pm 0.09$ & $0.90 \pm 0.08$ & $0.58 \pm 0.06$ & $1.28 \pm 0.06$ \\
$\quad$ Alendronate & $21.20 \pm 1.62^{\mathrm{a}}$ & $1.86 \pm 0.08$ & $0.79 \pm 0.08$ & $0.63 \pm 0.06$ & $1.31 \pm 0.05$ \\
\hline
\end{tabular}

Data expressed as mean \pm SEM. ${ }^{a} \mathrm{P}<0.05$ vs. non-diabetic control $(\mathrm{ND}+\mathrm{C})$ mice; ${ }^{\mathrm{b}} \mathrm{P}<0.05$ vs. diabetic control $(\mathrm{D}+\mathrm{C}) \mathrm{mice}$. FBG, fasting blood glucose; TC, total cholesterol; HDL-C, high-density lipoprotein cholesterol; LDL-C, low-density lipoprotein cholesterol; TG, triglyceride.

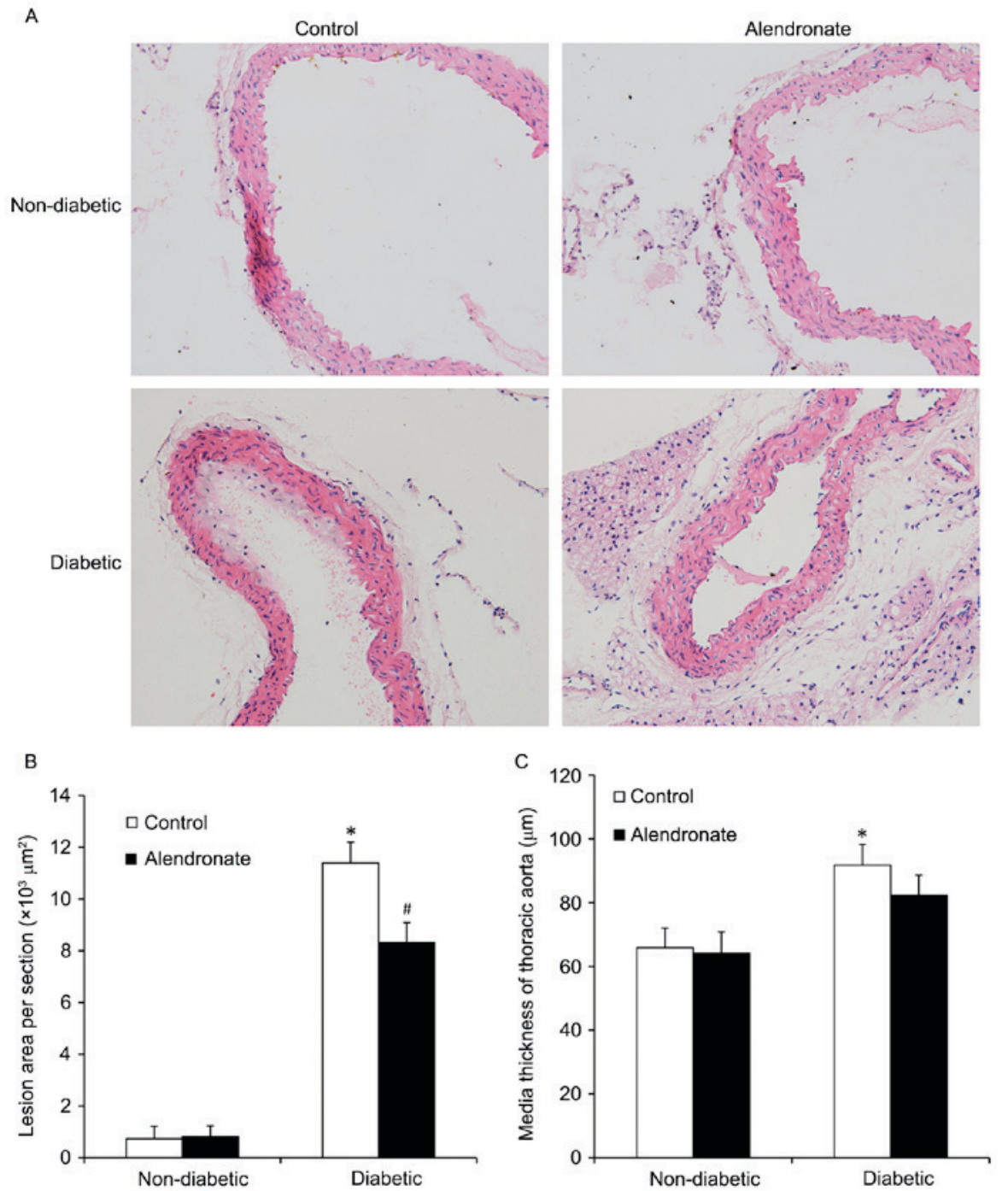

Figure 2. Histological analysis of aortas. (A) Representative images of aortas obtained from mice in non-diabetic control, non-diabetic alendronate, diabetic control, and diabetic alendronate groups. The sections of aorta were stained with hematoxylin and eosin (magnification, $\mathrm{x} 400)$. (B) Lesion areas and (C) media thickness were quantitatively analysised. Data were obtained from 6 mice for each group. Data expressed as mean \pm SEM. ${ }^{*}<<0.05$ vs. non-diabetic control mice; ${ }^{\#} \mathrm{P}<0.05$ vs. diabetic control mice.

Alendronate attenuated diabetic atherosclerosis development. The morphologic data of lesion area (LA) and media thickness (MT) were summarized in Fig. 2. In our study, STZ-induced diabetic mice developed moderate aortic atherosclerotic plaques, with a mean LA of $(11.39 \pm 0.81) \times 10^{3} \mu \mathrm{m}^{2}$ and MT of $91.74 \pm 6.52 \mu \mathrm{m}$. 16-week treatment of alendronate attenuated diabetic atherosclerosis development with a decline of LA $(8.32 \pm 0.77) \times 10^{3} \mu \mathrm{m}^{2}$ and MT 82.24 $\pm 6.39 \mu \mathrm{m}$. 


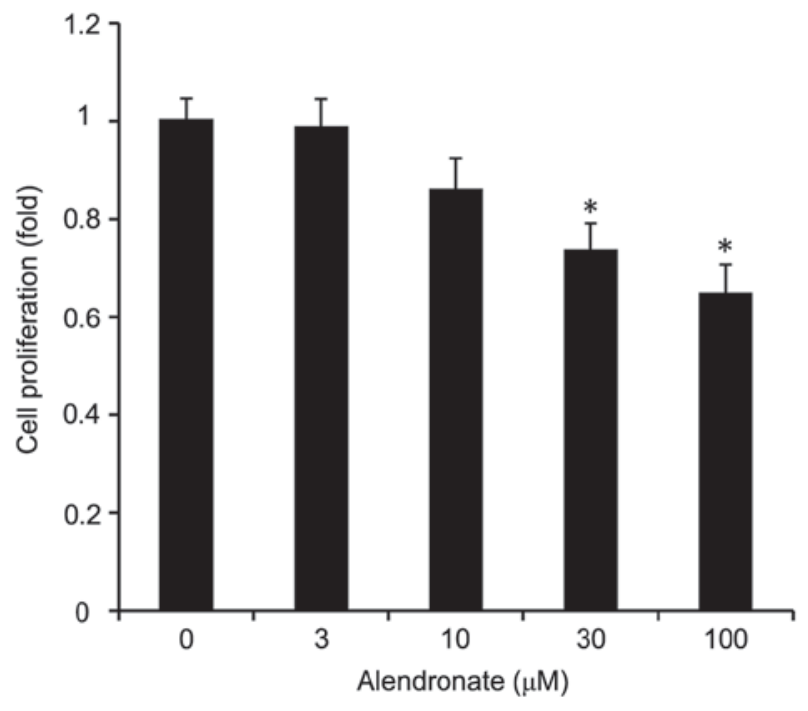

Figure 3. Effects of alendronate on high glucose $(22.2 \mathrm{mM})$ induced proliferation of VSMCs. VSMCs proliferation was assessed by MTT incorporation assay. VSMCs were treated with different concentrations of alendronate $(0,3,10,30$ and $100 \mu \mathrm{M})$ for $72 \mathrm{~h}$. Data expressed as mean $\pm \operatorname{SEM}(\mathrm{n}=6)$. ${ }^{*} \mathrm{P}<0.05$ vs. control group (treated with $0 \mu \mathrm{M}$ alendronate).

Alendronate inhibited the proliferation of VSMCs induced by high glucose. As an inhibitor of FPPS, alendronate dose-dependently inhibited the VSMCs proliferation induced by high glucose (Fig. 3). Alendronate at drug concentrations of 30 and $100 \mu \mathrm{M}$ remarkably inhibited the cell proliferation in a dose-dependent manner.

Alendronate had no effect on CSE expression. 16-week treatment with alendronate had no effect on aortic CSE expression of STZ-induced diabetic mice (Fig. 4). Similarly, in high glucose-treated VSMCs, alendronate $(0-100 \mu \mathrm{M})$ didn't change the expression of CSE expression (Fig. 4).

Alendronate suppressed the activation of small GTPases. Small GTPase (Ras, RhoA, or Rac1) activation depends on its conversion from the GDP- to the GTP-bound state. The levels of the GTP-bound active form of small GTPase (Ras, RhoA, or Rac1) in aorta and cultured VSMCs were determined by G-LISA kits. The total level of small GTPase (Ras, RhoA, or Rac1) was detected by western blot using its specific antibody. 16-week treatment with alendronate had no effect on aortic expression of total Ras, RhoA, or Racl in four groups of mice (data not shown). However, the GTP-Ras, RhoA, and Rac1 levels were decreased in diabetic alendronate $(\mathrm{D}+\mathrm{A})$ gourp (Fig. 5). Meanwhile, the same situation occurred in high glucose-treated VSMCs in vitro. Alendronate $(0-100 \mu \mathrm{M})$ had no effect on the expression of total Ras, RhoA, or Racl (data not shown). However, treatment with alendronate decreased GTP-Ras, RhoA, and Racl levels in a dose-dependent manner (Fig. 6).

Alendronate decreased the concentrations of total $\operatorname{Co}_{9}$ and $\operatorname{Co} Q_{10}$. In rodents, CoQ exists as two homologues, mainly $\mathrm{CoQ}_{9}$ with lesser amounts of $\mathrm{CoQ}_{10}$. In our study, alendronate dose-dependently decreased the total $\mathrm{CoQ}_{9}$ and $\mathrm{CoQ}_{10}$ concentrations in high glucose-treated VSMCs (Fig. 7).
Alendronate increased $\mathrm{H}_{2} \mathrm{~S}$ levels. Alendronate dose-dependently increased the $\mathrm{H}_{2} \mathrm{~S}$ levels in cultured medium, in which VSMCs were treated with high glucose (22.2 mM, Fig. 8).

\section{Discussion}

We herein demonstrate that inhibition of FPPS attenuates high glucose-induced VSMCs proliferation in vivo and in vitro, and the mechanisms probably involve inhibiting $\mathrm{H}_{2} \mathrm{~S}$ metabolism and decreasing small GTPases activation.

It is well established that accelerated proliferation of VSMCs is the fundamental event in the development of atherosclerosis in diabetes (4-6). In our previous study, high glucose (22.2 $\mathrm{mM}$ ) remarkably induced the VSMCs proliferation and FPPS upregulation in vitro and in vivo (11). Then, our present experiments found that treatment of alendronate attenuated the diabetic atherosclerosis process in STZ-induced mice, and that inhibition of FPPS dose-dependently attenuated high glucose-induced proliferation of VSMCs in vitro. All these findings suggested the important role of FPPS in VSMCs proliferation during diabetic accelerated atherosclerosis, but the mechanisms involved were not clear.

$\mathrm{H}_{2} \mathrm{~S}$ is a member of the endogenous gasotransmitter family, in addition to nitric oxide and carbon monoxide, and plays an important role in the cardiovascular and other systems (18-20). Endogenous $\mathrm{H}_{2} \mathrm{~S}$ is synthesized from L-cysteine in three different enzymatic reaction catalyzed by cystathionine $\beta$-synthase (CBS), CSE, or the sequential action of cysteine aminotransferase and 3-mercaptopyruvate sulfurtransferase (21). Among them, CSE is the pivotal $\mathrm{H}_{2} \mathrm{~S}$-producing enzyme in VSMCs, providing the main source of $\mathrm{H}_{2} \mathrm{~S}$ in cardiovascular system and suppressing VSMCs proliferation in different ways (22-24). On the other hand, $\mathrm{H}_{2} \mathrm{~S}$ is enzymatically scavenged or metabolized in mitochondria with the participation of CoQ (an important product of FPPS) $(25,26)$. Thus, endogenous $\mathrm{H}_{2} \mathrm{~S}$ concentration depends on its dynamic balance between synthesis and metabolism. In our study, alendronate dose-dependently increased $\mathrm{H}_{2} \mathrm{~S}$ levels, but decreased total CoQ content in high glucose-treated VSMCs, without any change of CSE expression. All these data indicated that inhibition of FPPS decreased the CoQ content, depressed the $\mathrm{H}_{2} \mathrm{~S}$ metabolism, increased endogenous $\mathrm{H}_{2} \mathrm{~S}$ concentration, and finally attenuated the high glucose-induced proliferation of VSMCs.

On the other hand, numerous molecular and cellular studies have demonstrated that small GTPases, consisting of the Ras, RhoA and Rac1, participate in the VSMCs proliferation triggered by hyperglycemia (27-31). The membrane localization and activation of small GTPase depend on its conversion from the GDP- to the GTP-bound state via the process of protein prenylation (32-34). In our study, G-LISA method could precisely determine the level of GTP-boud active small GTPase, so as to indicate the level of protein prenylation. Alendronate, in vivo and in vitro, inhibited small GTPases (Ras, RhoA, and Rac1) activation, but had no effect on the expressions of total Ras, RhoA, and Rac1, demonstrating that FPPS inhibition only affected the activated process of small GTPases, possibly by inhibition of their prenylation. Our presumption was that inhibition of FPPS decreased isoprenoid intermediates content (FPP and GGPP, 

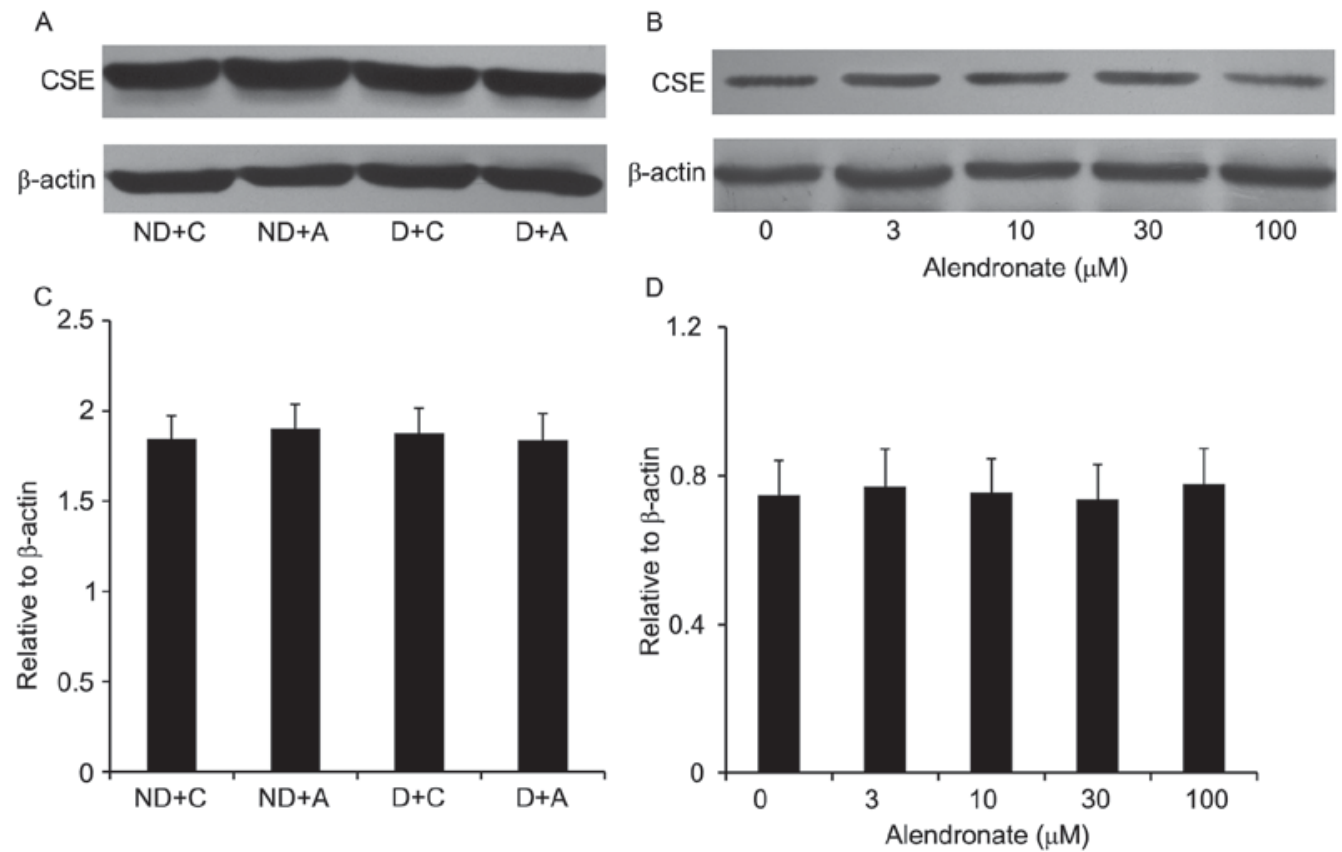

Figure 4. Effects of alendronate on the expressions of CSE. The protein expressions were detected by western blot analysis. (A) Representative blots and (C) densitometric average from aorta in vivo. (B) Representative blots and (D) densitometric average from VSMCs in vitro. $\beta$-actin was used as an internal control. Data expressed as mean \pm SEM $(n=6)$. CSE, cystathionine $\gamma$-lyase, is the main $\mathrm{H}_{2} \mathrm{~S}$-producing enzyme; ND+C, non-diabetic control group; ND+A, non-diabetic alendronate group; $\mathrm{D}+\mathrm{C}$, diabetic control group; $\mathrm{D}+\mathrm{A}$, diabetic alendronate group.

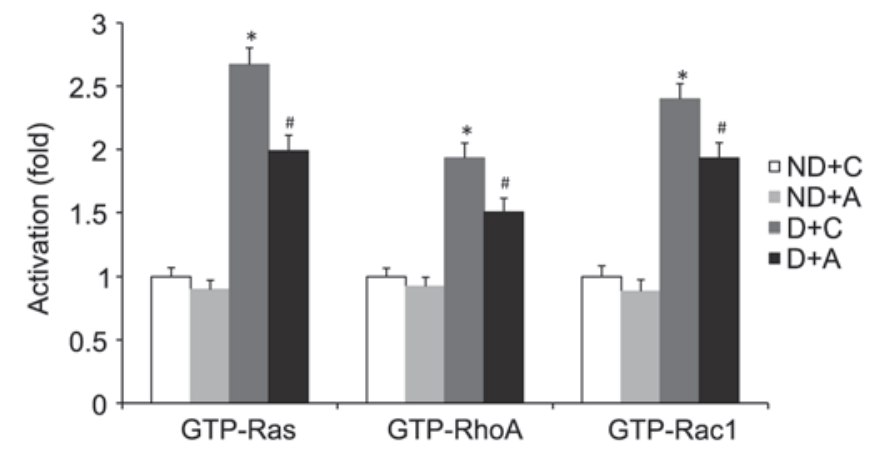

Figure 5. Effects of alendronate on small GTPase (Ras, RhoA, and Rac1) activation in aortas from non-diabetic or diabetic mice. Data expressed as mean $\pm \mathrm{SEM}$. ND+C, non-diabetic control group; $\mathrm{ND}+\mathrm{A}$, non-diabetic alendronate group; $\mathrm{D}+\mathrm{C}$, diabetic control group; $\mathrm{D}+\mathrm{A}$, diabetic alendronate group. ${ }^{*} \mathrm{P}<0.05$ vs. $\mathrm{ND}+\mathrm{C}$ group; ${ }^{\# \mathrm{P}}<0.05$ vs. $\mathrm{D}+\mathrm{C}$ group.

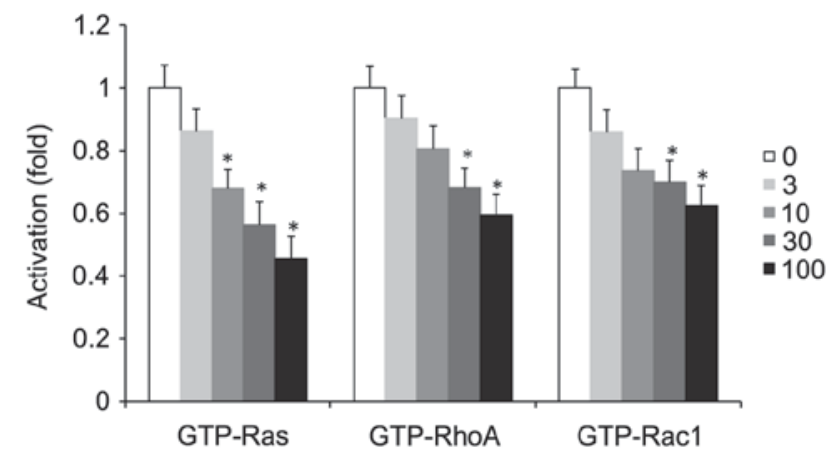

Figure 6. Effects of alendronate on small GTPase (Ras, RhoA, and Rac1) activation in high glucose-treated VSMCs. VSMCs were treated with different concentrations of alendronate $(0,3,10,30$ and $100 \mu \mathrm{M})$ for $72 \mathrm{~h}$. Data expressed as mean $\pm \operatorname{SEM}(n=6) .{ }^{*} \mathrm{P}<0.05$ vs. control group (treated with $0 \mu \mathrm{M}$ alendronate).
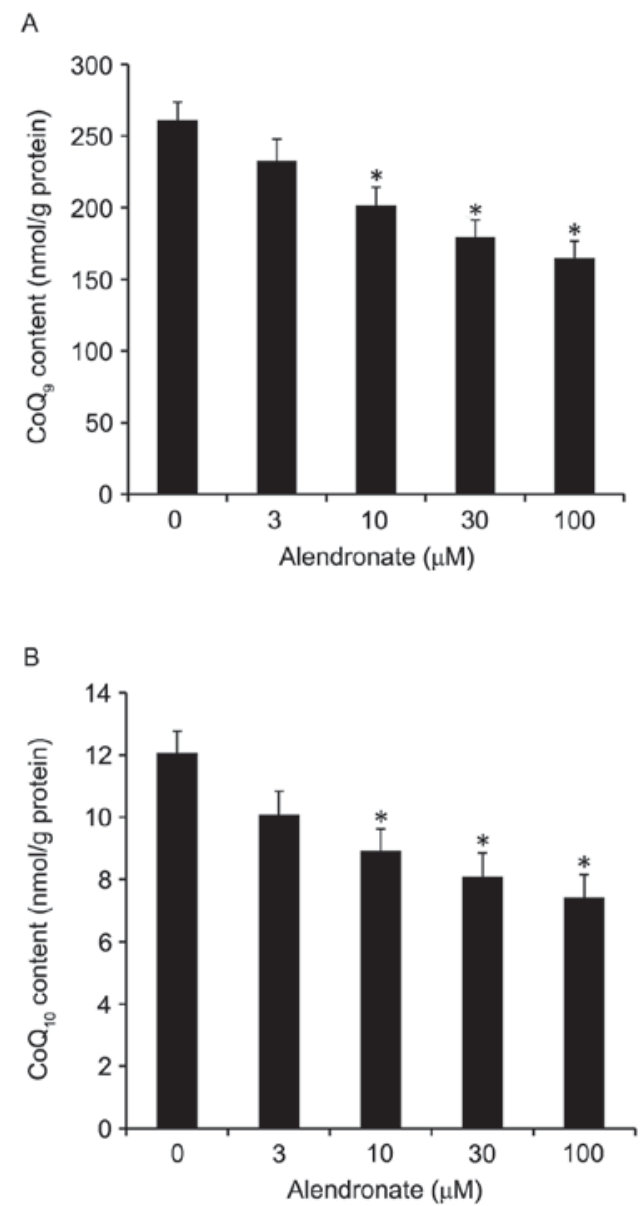

Figure 7.Effectsofalendronateontotal $\mathrm{CoQ}_{9} / \mathrm{CoQ}_{10}$ levelsinhighglucose-treated VSMCs. Total $\mathrm{CoQ}_{9}$ levels (A) and total $\mathrm{CoQ}_{10}$ levels (B) in alendronate $(0,3,10,30$ and $100 \mu \mathrm{M})$ treated VSMCs. Data expressed as mean \pm SEM $(\mathrm{n}=6) .{ }^{*} \mathrm{P}<0.05$ vs. control group (treated with $0 \mu \mathrm{M}$ alendronate) 


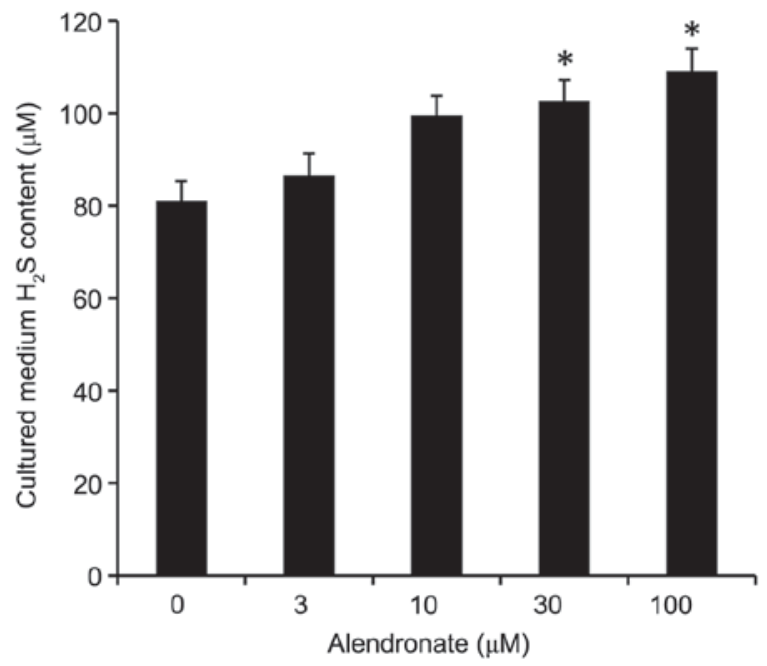

Figure 8. Effects of alendronate on $\mathrm{H}_{2} \mathrm{~S}$ levels in cultured medium of VSMCs. High glucose-treated VSMCs were incubated with alendronate $(0,3,10,30$ and $100 \mu \mathrm{M})$. Data expressed as mean \pm SEM $(\mathrm{n}=6)$. ${ }^{*} \mathrm{P}<0.05$ vs. control group (treated with $0 \mu \mathrm{M}$ alendronate).

Fig. 1), depressed small GTPases (Ras, RhoA, and Rac1) activation, and finally attenuated the high glucose-induced proliferation of VSMCs.

Furthermore, alendronate, an FPPS inhibitor used in our study, is one of the bisphosphonates, using widely in bone-related disorders (35). One concern is that the half-life of bisphosphonates in the circulation is short, and they enter rapidly and extensively into bone because of their high affinity to the calcium and hydroxyapatite crystals (12). During our in vitro study, alendronate directly acted on VSMCs and exerted inhibitory effects, but whether it is still working when the drug is applied on the whole animals? Fortunately, there are supportive evidences. Bisphosphonates have also been reported to accumulate markedly in the aortas of both healthy and atherosclerotic rabbits in vivo (35) and in human internal mammary arteries in vitro (36). Thus, this leads to the hypothesis that bisphosphonates, when used in vivo, may also exert direct effects on VSMCs, which are the major cellular components of vascular wall. Indeed, our in vivo study confirmed the protective effect of FPPS inhibition on diabetic accelerated atherogenic process.

In conclusion, our study provided the experimental evidences that FPPS inhibition attenuated the high glucose-induced proliferation of VSMCs in vivo and in vitro, though depressing $\mathrm{H}_{2} \mathrm{~S}$ metabolism and suppressing small GTPases (Ras, RhoA, and Rac1) activation. Although there are many essential differences between experimental and clinical studies, our finding represents a potentially promising therapeutic strategy for the treatment of diabetic macrovascular disease in the future.

\section{Acknowledgements}

This study was supported by the National Natural Science Foundation of China (no. 81500616), Natural Science Foundation of Zhejiang Province (no. LQ13H070001 and LQ16H070002), Medical Science and Technology Project of Zhejiang Province (no. 2013KYA062, 2015KYA076 and
2016KYA012), and Traditional Chinese Medicine Project of Zhejiang Province (no. 2014ZB006).

\section{References}

1. Nickerson HD and Dutta S: Diabetic complications: Current challenges and opportunities. J Cardiovasc Transl Res 5: 375-379, 2012.

2. Schmidt AM: Recent highlights of ATVB: Diabetes mellitus. Arterioscler Thromb Vasc Biol 34: 954-958, 2014.

3. Porter KE and Riches K: The vascular smooth muscle cell: A therapeutic target in type 2 diabetes? Clin Sci 125: 167-182, 2013.

4. Gray SP and Jandeleit-Dahm K: The pathobiology of diabetic vascular complications-cardiovascular and kidney disease. J Mol Med 92: 441-452, 2014.

5. Chait A and Bornfeldt KE: Diabetes and atherosclerosis: Is there a role for hyperglycemia? J Lipid Res 50 (Suppl): S335-S339, 2009.

6. Rudijanto A: The role of vascular smooth muscle cells on the pathogenesis of atherosclerosis. Acta Med Indones 39: 86-93, 2007.

7. Dhar MK, Koul A and Kaul S: Farnesyl pyrophosphate synthase: A key enzyme in isoprenoid biosynthetic pathway and potential molecular target for drug development. N Biotechnol 30: 114-123, 2013.

8. Sun S and McKenna CE: Farnesyl pyrophosphate synthase modulations: A patent review (2006-2010). Expert Opin Ther Pat 21: 1433-1451, 2011.

9. Goldstein JL and Brown MS: Regulation of the mevalonate pathway. Nature 343: 425-430, 1990.

10. Buhaescu I and Izzedine H: Mevalonate pathway: A review of clinical and therapeutical implications. Clin Biochem 40: 575-584, 2007.

11. Chen GP, Zhang XQ, Wu T, Li L, Han J and Du CQ: Alteration of mevalonate pathway in proliferated vascular smooth muscle from diabetic mice: Possible role in high-glucose-induced atherogenic process. J diabetes Res 2015: 379287, 2015.

12. Russell RG: Bisphosphonates: The first 40 years. Bone 49: 2-19, 2011.

13. Chen GP, Li L, Yang Y, Fu M, Yao L, Wu T, Zhang XQ and Hu SJ: Chronic inhibition of Farnesyl pyrophosphate synthase improves endothelial function in spontaneously hypertensive rats. Biochem Pharmacol 80: 1684-1689, 2010.

14. Mehrhof FB, Schmidt-Ullrich R, Dietz R and Scheidereit C: Regulation of vascular smooth muscle cell proliferation: Role of NF-kappaB revisted. Circ Res 96: 958-964, 2005.

15. Chen GP, Yao L, Lu X, Li L and Hu SJ: Tissue-specific effects of atorvastatin on 3-hydroxy-3-methylglutarylcoenzyme A reductase expression and activity in spontaneously hypertensive rats. Acta Pharmacol Sin 29: 1181-1186, 2008.

16. Lang JK, Gohil K and Packer L: Simultaneous determination of tocopherols, ubiquinols, and ubiquinones in blood, plasma, tissue homogenates, and subcellular fractions. Anal Biochem 157: 106-116, 1986.

17. Zhu YZ, Wang ZJ, Ho P, Loke YY, Zhu YC, Huang SH, Tan CS, Whiteman M, Lu J and Moore PK: Hydrogen sulfide and its possible roles in myocardial ischemia in experimental rats. J Appl Physiol (1985) 102: 261-268, 2007.

18. Xu S, Liu Z and Liu P: Targeting hydrogen sulfide as a promising therapeutic strategy for atherosclerosis. Int J Cardiol 172: 313-317, 2014.

19. Vandiver M and Snyder SH: Hydrogen sulfide: A gasotransmitter of clinical relevance. J Mol Med (Berl) 90: 255-263, 2012.

20. Gadalla MM and Synder SH: Hydrogen sulfide as a gasotransmitter. J Neurochem 113: 14-26, 2010.

21. Whiteman M, Le Trionnaire S, Chopra M, Fox B and Whatmore J: Emerging role of hydrogen sulfide in health and disease: Critical appraisal of biomarkers and pharmacological tools. Clin Sci 121: 459-488, 2011.

22. Mani S, Untereiner A, Wu L and Wang R: Hydrogen sulfide and the pathogenesis of atherosclerosis. Antioxid Redox Signal 20: 805-817, 2014.

23. Qiao W, Chaoshu T, Hongfang J and Junbao D: Endogenous hydrogen sulfide is involved in the pathogenesis of atherosclerosis. Biochem Biophys Res Commun 396: 182-186, 2010.

24. Elsey DJ, Fowkes RC and Baxter GF: Regulation of cardiovascular cell function by hydrogen sulfide $(\mathrm{H}(2) \mathrm{S})$. Cell Biochem Funct 28: 95-106, 2010. 
25. Martelli A, Testai L, Marino A, Breschi MC, Da Settimo F and Calderone V: Hydrogen sulphide: Biopharmacological roles in the cardiovascular system and pharmaceutical perspectives. Curr Med Chem 19: 3325-3326, 2012.

26. Beltowski J and Jamroz-Wisniewska A: Modulation of $\mathrm{H}(2) \mathrm{S}$ metabolism by statins: A new aspect of cardiovascular pharmacology. Antioxid Redox Signal 17: 81-94, 2012.

27. Chen J, Dai M and Wang Y: Paeonol inhibits proliferation of vascular smooth muscle cells stimulated by high glucose via Ras-Raf-ERK1/2 signaling pathway in coculture model. Evid Based Complement Alternat Med 2014: 484269, 2014.

28. Zhao Y, Liu J, Li L, Liu L and Wu L: Role of Ras/PKCzeta/MEK/ERK1/2 signaling pathway in angiotensin II-induced vascular smooth muscle cell proliferation. Regul Pept 128: 43-50, 2005.

29. Ishiko K, Sakoda T, Akagami T, Naka T, Doi T, Tsujino T, Masuyama T and Ohyanagi M: Hyperglycemia induced cell growth and gene expression via the serum response element through RhoA and Rho-kinase in vascular smooth muscle cells. Prep Biochem Biotechnol 40: 139-151, 2010.

30. Sawada N, Li Y and Liao JK: Novel aspects of the roles of Rac1 GTPase in the cardiovascular system. Curr Opin Pharmacol 10: $116-121,2010$.
31. Zhu LH, Wang L, Wang D, Jiang H, Tang QZ, Yan L, Bian ZY, Wang XA and Li H: Puerarin attenuates high-glucose and diabetes-induced vascular smooth muscle cell proliferation by blocking PKCbeta2/Rac1-dependent signaling. Free Radic Biol Med 48: 471-482, 2010.

32. McTaggart SJ: Isoprenylated proteins. Cell Mol Life Sci 63: 255-267, 2006.

33. Roskoski R Jr: Protein prenylation: A pivotal posttranslational process. Biochem Biophys Res Commun 303: 1-7, 2003.

34. Casey PJ: Protein lipidation in cell signaling. Science 268: 221-225, 1995.

35. Ylitalo R, Mönkkönen J, Urtti A and Ylitalo P: Accumulation of bisphosphonates in the aorta and some other tissues of healthy and atherosclerotic rabbits. J Lab Clin Med 127: 200-206, 1996.

36. Ylitalo R, Kalliovalkama J, Wu X, Kankaanranta H, Salenius JP, Sisto T, Lähteenmäki T, Ylitalo P and Pörsti I: Accumulation of bisphosphonates in human artery and their effects on human and rat arterial function in vitro. Pharmacol Toxicol 83: 125-131, 1998. 